\title{
SUBSYSTEM ANALYSIS/OPTIMIZATION FOR THE X-34 MAIN PROPULSION SYSTEM
}

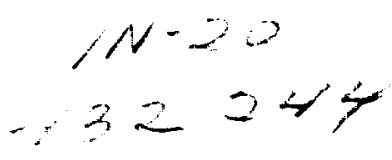

\author{
J. P. McDonald ${ }^{*}$, A. Hedayat ${ }^{\dagger}$, T. M. Brown ${ }^{*}$, and K. C. Knight ${ }^{\ddagger}$ \\ Propulsion Department \\ Sverdrup Technology, Inc., MSFC Group \\ Huntsville, AL 35806 \\ R. H. Champion, Jr. ${ }^{\S}$ \\ Propulsion Laboratory \\ NASA Marshall Space Flight Center, AL 35812
}

\begin{abstract}
The Orbital Sciences Corporation X-34 vehicle demonstrates technologies and operations key to future reusable launch vehicles. The general flight performance goal of this unmanned rocket plane is Mach 8 flight at an altitude of 250,000 feet. The Main Propulsion System (MPS) supplies liquid propellants to the main engine, which provides the primary thrust for attaining mission goals. Major MPS design and operational goals are aircraft-like ground operations, quick turnaround between missions, and low initial/operational costs. Analyses related to optimal MPS subsystem design are reviewed in this paper. A pressurization system trade weighs maintenance/reliability concerns against those for safety in a comparison of designs using pressure regulators versus orifices to control pressurant flow. A propellant dump/feed system analysis weighs the issues of maximum allowable vehicle landing weight, trajectory, and MPS complexity to arrive at a final configuration for propellant dump/feed systems.

\begin{tabular}{ll}
\hline$*$ & Engineer, Member AIAA. \\
$\dagger$ & Engineer, Senior Member AIAA. \\
$\ddagger$ & Lead Engineer, Member AIAA. \\
$\S$ & X-34 Product Development Team Lead, \\
& Member AIAA.
\end{tabular}

Copyright $\odot 1998$ by the American Institute of Aeronautics and Astronautics, Inc. No copyright is asserted in the United States under Title 17, U.S. Code. The U.S. Government has a royalty-free license to exercise all rights under the copyright claimed herein for Governmental purposes. All other rights are reserved by the copyright owner.
\end{abstract}

Lastly, design of the liquid oxygen dump system integrated Computational Fluid Dynamic simulation results for a single component into a system level one-dimensional flow analyses to ensure optimal design of a dump system exit orifice which prevents vaporization in the dump system.

\section{INTRODUCTION}

The X-34 program demonstrates operations, propulsion and structural technologies key to future reusable launch vehicles. Program goals include aircraft-like ground operations, quick turnaround between missions, and low acquisition and operating costs. An X-34 mission includes captive carry to an altitude of 38,000 feet, engine start in a horizontal orientation after separation from the carry vehicle, powered flight, and glide back to a runway landing. Thrust comes from a nominal $60,000 \mathrm{lbf}$ thrust version of the MSFC Fastrac engine ${ }^{l}$, which burns Rocket Propellant 1 (RP-1) grade kerosene fuel with liquid oxygen (LOX) oxidizer. The X-34 is also designed for abort scenarios where the engine either completely fails to operate or shuts down prematurely. More comprehensive reviews of the $\mathrm{X}-34$ program and propulsion systems are provided by Sgarlata and Winters ${ }^{2}$ and Sullivan and Winters ${ }^{3}$. The National Aeronautics and Space Administration (NASA)/Marshall Space Flight Center (MSFC) and the Sverdrup Technology/MSFC Group provide the analysis and design support for the X-34 Main Propulsion System (MPS). Hedayat et al. ${ }^{4}$ provides an overview of the propellant tank pressurization, pneumatic, and tank vent subsystems. Brown et al. ${ }^{5}$ provides an overview of systems for propellant 
storage, conditioning, and dumping. McDonald et al. ${ }^{6}$ provides an overview of the propellant feed systems. This paper reviews four specific analyses performed to help guide and/or optimize subsystem design.

The MPS uses gaseous helium (GHe) pressurant to deliver propellant from the storage tanks to the engine turbopumps at the required flow rates and pressures. In the baseline pressurization system design, pressure regulators control the flow rate of $\mathrm{GHe}$ to the propellant tanks. Due to regulator maintenance/reliability concerns, the MPS team considered two alternate systems utilizing orifices to control the pressurant flow rate. In addition to considering normal operational flow requirements, each system was analyzed with respect to the vent/relief valve response time and the ability of the overall vent system to relieve the steady state GHe flow resulting from a pressurization system failure.

The second section addresses the issue of propellant residual mass and its impact on MPS dump/feed system configurations. The $\mathrm{X}-34$ vehicle is designed for both powered flight and unpowered abort missions. Residual propellant mass after powered flight represents unrealized payload potential and/or flight performance, while excessive abort mission residuals overload the vehicle landing gear. The trades between meeting powered flight and abort mission propellant residual requirements and reducing system complexity/cost are presented along with the propellant residual analysis methodology.

The third analysis involves the detailed design of an exit orifice for the LOX dump line. The X-34 flight computer integrates flow rate data from an obstruction type flowmeter to track the propellant mass remaining, and thus vehicle center of gravity, during propellant jettison. A LOX dump system exit orifice prevents vaporization within the dump line due to locally low static pressures. The pressure drop across the orifice is optimized to prevent cavitation within the flowmeter, without unnecessarily limiting LOX dump flow, by combining Computational Fluid Dynamic simulations of the orifice with a one dimensional system level flow analysis.

\section{PRESSURIZATION SYSTEM TRADE STUDY}

The ullage pressure ranges supplying the necessary flow rate and pump inlet requirements were determined by feed system analyses ${ }^{6}$ to be $55-61$ psia and 47-53 psia for the LOX and RP-1 tanks, respectively. Two pressurization system designs were considered for controlling the ullage pressure in the
LOX and RP-1 storage tanks. Both designs utilize solenoid valves, under feedback control from ullage pressure sensors, to maintain the desired propellant tank ullage pressure. The design approaches differ in their means of controlling the GHe flow rate from the supply tanks to the propellant tanks while the solenoid flow control valves are open. The original design uses regulators to control the pressure of $\mathrm{GHe}$ upstream of the solenoid valves. Two orifice based systems were considered later in the program to address concerns regarding regulator reliability and maintenance requirements. All systems were sized to meet engine turbopump requirements and then analyzed for their compatibility with the existing propellant tank vent/pressure-relief systems.

All pressurization system designs must provide two-fault tolerance to a catastrophic event while attached to the L-1011 carry vehicle. In short, the design must allow two component failures without resulting in a condition that may damage the carry vehicle and/or its crew.

\section{Design Options}

All design options initially store $\mathrm{GHe}$ at $530 \mathrm{R}$ and 5000 psia in tanks totaling $25.2 \mathrm{ft}^{3}$ volume. A latching solenoid valve isolates the stored helium until tank pressurization. Press system differences begin downstream of the latching solenoid valve. For all three design options, solenoid valves meter $\mathrm{GHe}$ to the propellant tanks, thus maintaining the ullage pressure within the necessary range for a given tank. When tank ullage pressure sensor output to the flight computer falls below the lower set point, the flight computer commands the solenoid valve(s) open, and the ullage pressure increases until it passes the upper set point where the solenoid valve is commanded to close. The solenoid metering valves normally fail closed. Thus, a multi-valve, parallel arrangement is used to provide operational redundancy.

Figure 1 illustrates the original regulator based design option. Immediately downstream of the latching solenoid valve, $\mathrm{GHe}$ pressure is regulated to 350 psia. Dual regulators in series provide redundancy for both operational and safety purposes. The set pressure of the downstream (second) regulator is slightly above that of the first, such that the second remains fully open during normal operation. Downstream of the regulators, the pressurization line branches into two identical systems controlling LOX or RP-1 tank ullage pressure. A single solenoid valve meters flow to the tank, while a redundant solenoid valve in parallel provides operational and safety redundancy. Check valves in both the LOX and RP-1 flow metering 


\section{Preliminary Draft}

circuits prevent the upstream migration, and possible mixing, of propellants in the pressurization system.

Figure 2 illustrates the single orifice design option. Dual solenoid valves in parallel meter the flow of GHe to each propellant tank and provide operational redundancy in the event of a solenoid valve failing closed. Check valves prevent the mixing of LOX and RP-1 in the pressurization system, and a single sharp-edged orifice controls the rate of $\mathrm{GHe}$ flow to the tanks. The orifice size is chosen to just meets engine turbopump requirements at the end of a full performance mission when the pressurant storage tank pressure is estimated to be 530 psia, Being of fixed geometry, unlike the regulator system, this orifice size provides a flow rate substantially larger than needed early in the mission, thus placing greater demands on vent system performance relative to the regulator design.

Figure 3 illustrates the multiple orifice design consisting of three parallel flow paths each containing a solenoid valve and orifice in series. Two of the solenoid valves are commanded by the flight computer to control tank pressure, and the third valve provides operational redundancy. Compared to the single orifice design, the flow area of each orifice is smaller, thus reducing the GHe flow rate, and tank pressure rise rate, in the event a single solenoid metering valve fails in the open position.

\section{Two Fault Tolerance}

Prior to propellant tank pressurization, open failure of the latching solenoid valve constitutes a first fault. For much of the time preceding tank pressurization, the ullage volumes are at their smallest for both the LOX and RP-1 tanks, thus placing greater demands on the response time of the vent/relief system. The latching solenoid valve is no longer a viable fault after the it opens for tank pressurization.

During the time before pressurization, the two faults for the regulator design are failure of the latching solenoid valve in the open position and failure of the upstream regulator. Thus, the downstream regulator mitigates against any catastrophic event. Two distinct failure pathways exist after opening the latching solenoid valve. First, the failure of both regulators comprises two faults, and the solenoid valves mitigate catastrophic failure in the form of tank overpressurization. Second, both solenoid valves failing open comprises two faults, and the vent/relief system must prevent tank overpressurization.

Prior to tank pressurization, the single solenoid valve design allows open failures of the latching solenoid valve and a single solenoid flow control valve as two faults. The vent/relief system must then mitigate tank overpressurization. After tank pressurization, the first fault is for a single solenoid flow control valve to fail in the open position. Failure of the second solenoid flow control valve does not constitute a second fault, since the orifice limits the GHe mass flow rate to the tank. The second fault is failure of the vent function of the vent/relief valve, thus requiring the relief function of the vent/relief valve for catastrophic event mitigation. While able to relieve tank overpressurization due to other causes, the relief function alone is inadequate in the event of a pressurization system failure. Thus, the single orifice system is not a viable candidate in light of the two fault tolerance requirement. The third design increases the number of orifice restricted flow paths to overcome the above limitation.

Prior to tank pressurization, the multiple orifice design provides two faults in the latching solenoid valve failing open and a single flow control solenoid failing open. Thus, the vent function of the vent relief valve provides catastrophic failure mitigation. After tank pressurization, the two faults are failure of two flow control solenoid valves in the open position, which requires mitigation by the vent function of the vent relief valve.

Based on the two fault tolerant to a catastrophic event criteria, the vent systems must be analyzed for their ability to prevent the propellant tank pressure(s) from rising above their proof values for the following pressurization system failure scenarios: 1) regulator design with two solenoid flow control valve failures and proper regulator operation, and 2) multiple orifices with two flow control solenoid valve failures. Two types of analyses are necessary. The first addresses whether the vent valve responds quickly enough to prevent tank overpressurization, and the second addresses the steady state relief capability of the vent valve.

\section{Vent Valve Response Time}

In the event of a pressurization system failure, the vent valve must respond fast enough to prevent propellant tank pressures from rising above their proof ratings. The proof pressures for the LOX and RP-1 storage tanks are 113 psig and 150 psig, respectively. Though a catastrophic failure does not occur unless the tanks are pressurized over their burst ratings, the proof criteria safeguards against the need to repair/replace the propellant tanks in the event of a pressurization system failure. The GHe inlet mass flow rate, initial propellant tank pressure and ullage volume, and GHe temperature determine the time 
required for a propellant tank to reach its proof pressure.

The one-dimensional fluid circuit analysis code GFSSP $^{7}$ was used to find the worst case GHe mass flow rates to the propellant tanks for the two failure scenarios above. Failure of two solenoid flow control valves in the regulator design results in $\mathrm{GHe}$ mass flow rates of $0.35 \mathrm{lbm} / \mathrm{s}$ and $0.10 \mathrm{lbm} / \mathrm{s}$ to the LOX and RP-1 tanks, respectively. Failure of two solenoid flow control valves in the multiple orifice system results in flow rates of $1.39 \mathrm{lbm} / \mathrm{s}$ and $0.38 \mathrm{lbm} / \mathrm{s}$ to the LOX and RP-1 tanks, respectively. These worst case flow rates remain constant as propellant tank pressure rises, since the GHe flow chokes in the pressurization system for both regulator and multiple orifice designs.

Figure 4 illustrates the time required for the ullage pressure in each propellant tank to rise from 75 psia to tank proof. Two ullage volume cases were considered for the LOX tank. The $4.7 \mathrm{ft}^{3}$ ullage corresponds to the time between tank fill and propellant conditioning at $38,000 \mathrm{ft}$. During this time, the tanked LOX warms due to heat transfer into the tank. Controlled venting to 13 psia cools the LOX by boiling and GOX expulsion from the tank. The $10 \mathrm{ft}^{3}$ ullage corresponds to the smallest expected ullage volume after conditioning. The minimum RP-1 ullage is $3.6 \mathrm{ft}^{3}$. Two bars for each case represent extremes of the ullage temperature at the GHe inlet temperature and the ullage temperature at the propellant temperature. The vertical band represents the probable range of times required for the vent valve to open fully. The valve specification is for 1 second to full open. Actual valve response time is likely faster, but certainly no better than the 0.5 second lower limit in Figure 4.

Results in Figure 4 indicate that only the regulator design avoids LOX tank overpressurization with the current vent system. Even the regulator system is marginal for the $4.7 \mathrm{ft} 3$ ullage case. Both regulator and multiple orifice designs are predicted to prevent RP-1 tank overpressurization, with the multiple orifice design being marginal.

\section{Steady Flow Vent Valve Operation}

Analysis of the regulator design using GFSSP reveals the current vent systems to prevent overpressurization for both LOX and RP-1 tanks. The multiple orifice design is compatible with the current RP-1 vent system, but not with the LOX vent system. The current LOX vent system uses an orifice restriction at its exit to limit GOX velocities in the system during controlled vent, thus eliminating concerns regarding particle impact ignition of the aluminum flow path in the LOX vent valve. If the flow velocities are too high, an entrained particle may have enough kinetic energy to ignite the aluminum flow path in such an oxygen rich environment. Removal of the exit orifice is not a viable option, and the redesign/replacement of the vent valve is likely too costly in terms of budget and time.

\section{Trade Study Conclusions}

Only the regulator based design meets all necessary performance and safety requirements set forth above. The multiple orifice system is acceptable only if the tank overpressurization criteria changes from proof pressure to burst pressure. A burst pressure criteria meets the two fault tolerance requirement, but propellant tank pressurization above proof requires removal, and possible replacement, of the affected $\operatorname{tank}(\mathrm{s})$. The final decision was made to use the regulator based system, as the maintenance and reliability concerns associated with it are less troublesome than the redesign and safety issues associated with the orifice based system.

\section{MPS DUMP/FEED SYSTEM ANALYSIS}

Each propellant tank must have an outlet(s) for engine feed during a normal mission and propellant dump in the event of mission abort. The optimal location of a tank outlet depends upon the tank geometry and the propellant orientation due to body forces during tank terminal drain. The propellant orientations for normal engine feed and abort mission scenarios differ by roughly $90^{\circ}$, thus ideally requiring two separate tank outlets to minimize propellant residuals for each case.

\section{Propellant Tank Desian/Layout}

Figure 5 is an elevation view of the final X-34 MPS configuration. The presence of wing structure in the middle of the LOX storage tanks necessitated a dual LOX tank design. Though necessary for structural reasons, the dual tank design complicates many aspects of MPS analysis/design, including propellant residual minimization. To minimize the risk associated with tank design/manufacture, MPS penetrations are only allowed through a manway near the center of each tank end dome. Lines penetrating the tank must be cantilevered to this manway, and cannot be attached internally to the tank walls.

A compartmentalized tank design, similar to that used on the earlier X-15 rocket plane, minimizes the effect of propellant motion on vehicle center of gravity during flight. Limiting vehicle center of 


\section{Preliminary Draft}

gravity motion is especially important in the event of premature engine shut down, where partially full propellant tanks could otherwise result in sudden center of gravity shifts of several feet. Check valves mounted near the top and bottom of each internal dome control propellant motion such that each tank empties one compartment at a time from front to rear, thus allowing knowledge of vehicle center of gravity location during flight as a function of remaining propellant mass. The $\mathrm{X}-34$ flight computer requires knowledge of the vehicle center of gravity location for control during flight.

\section{Preliminary Dump/Feed System Layout}

Figure 6 illustrates the first layout of the X-34 dump/feed system. The RP-1 tank uses a single outlet for both dump and feed functions. Though not optimal from a propellant residual standpoint, it was hoped that a single tank outlet would reduce MPS dry mass and system complexity. The RP- 1 combination dump/feed line requires two pneumatic valves, located towards the vehicle rear, to isolate dump and feed functions. The forward LOX tank uses separate lines for dump and feed functions. A feedline directly connects to the aft LOX tank, and a dump line connects to the aft LOX tank dump line near the vehicle rear. A pneumatic valve in the forward LOX tank dump line ensures isolation of dump and feed functions. Separate outlets for dump and feed functions minimize propellant residuals in aft LOX tank as well. A pneumatic shut-off valve in the LOX dump line and pneumatic pre-valve in the LOX feedline complete the initial system layout.

The system in Figure 4 functions properly for engine feed, but obviates the purpose of tank compartmentalization when dumping propellants during an abort mission. The dump line connecting forward and aft LOX tanks allows the aft tank to empty before the forward tank, thus resulting in an abort mission LOX residual level qualitatively represented by the shaded region in Figure 4. Changes had to be made to the LOX tank design to preserve tank compartmentalization.

\section{LOX Dump/Feed System Layout Revision}

Preservation of LOX tank compartmentalization for both dump and feed operations requires a direct connection between the aft most compartment of the forward LOX tank and the forward most compartment of the aft LOX tank. Separate forward LOX tank outlets for dump and feed functions are ideal from a LOX residual viewpoint, but such a design requires a pneumatic valve in the liquid interconnect to isolate the dump function. The pneumatic valve in the feed connector prevents the passage of pressurant into the aft tank prior to emptying the forward tank through the dump connector. Though optimal from a propellant residual perspective, space limitations between the forward and aft LOX tanks prevent the placement of both a pneumatic valve and flexible joints in the feed connector. Thus, a single line must serve as both dump and feed connector between the LOX tanks. At this stage, the question remained as to whether a single pickup inside the RP-1 tank, serving both dump and feed functions, would meet both engine feed and abort mission propellant residual requirements.

\section{RP-1 Combination Dump/Feed Outlet Feasibility}

The feasibility of a single propellant pickup inside the RP-1 tank depends primarily upon the propellant orientation for abort and engine feed scenarios, the LOX and RP-1 tank internal check valve designs, and the forward LOX and RP- 1 tank propellant pickup designs. At the time of this feasibility analysis, none of the above were clearly defined.

The X-34 MPS system specification requires a minimum $27,500 \mathrm{lbm}$ of LOX and RP-1 propellants to be usable for nominal engine operation at a LOX/RP- 1 mass ratio of 2.187 , as well as the ability to dump $95 \%$ of the total initial propellant load within 300 seconds during an abort mission. The usable propellant and dump completion requirements are necessary to meet flight performance goals and avoid damaging the vehicle landing gear, respectively.

The feasibility analysis below bases the $95 \%$ dump completion requirement on the $27,500 \mathrm{lbm}$ usable propellant requirement, thus resulting in a slightly more conservative $1375 \mathrm{lbm}$ allowable propellant residual mass. Basing the dump completion percentage on the usable propellant requirement establishes a fixed goal which is slightly more conservative with respect to landing mass.

\section{Hypothetical Tank Internal Configuration}

At the time of this feasibility study, no firm designs existed for the propellant tank internal check valves and outlets. Thus, the feasibility analysis assumed generic designs for these components exhibiting characteristics and performance believed representative of a final design. Figure 8 illustrates this generic design. A siphon tube following the tank contour represents the tank outlet. The siphon "cut-angle" relative to the tank centerline determines the siphon terminus inside the tank. A cut-angle of 
$0^{\circ}$ corresponds to a simple penetration at the manway center with no extension into the tank, while a cut-angle of $-90^{\circ}$ corresponds to the pickup tube terminating at the bottom of the tank compartment.

Abort mission residuals depend strongly upon the mounting height of the lower internal check valves as illustrated in Figure 8 . When the liquid level in a tank compartment uncovers a check valve, the GHe pressurant passes directly into the adjoining compartment without forcing liquid ahead of it. The generic design assumes a 4 inch height for all of the lower check valves, which was believed a reasonable design goal for check valve mounting. All final check valve heights in the final tank design are at, or below, this assumed value.

\section{Analysis Methodology}

The analysis approach determines the g-angle required in an abort mission (DRM3) to achieve dump to $95 \%$ completion as a function of siphon cut-angle in the forward LOX tank. The g-angle is the angle, illustrated in Figure 8 , between the resultant body acceleration vector and the vehicle roll-axis. The analysis proceeds as: 1) assume a forward LOX tank siphon cut-angle and determine the usable LOX for engine feed in a full performance (DRM2) mission, 2) determine the required DRM2 RP-1 mass based on a 2.187 LOX/RP-1 ratio, 3) determine the RP-1 tank siphon cut-angle just providing the required DRM2 RP-1 mass from (2), and 4) determine the DRM3 g-angle required to dump to $95 \%$ completion for the above forward LOX and RP-1 tank siphon cut-angles.

To aid in this, and future, analyses, the dependence of propellant residual on g-angle and siphon cut-angle was mapped for each tank. Each map consists of a family of curves representing different cut-angles, and each curve represents propellant residual as a function of g-angle. As an example, Figure 9 illustrates the forward LOX tank residual map. All of the maps neglect the impact of propellant dropout at the tank outlets on propellant residual mass for both DRM2 and DRM3 cases.

Determining the DRM2 forward LOX tank residual requires knowledge of the g-angle at the moment when the forward LOX tank empties. Assuming all LOX tank ullage moves into the forward LOX tank through the upper check valves prior to emptying the forward LOX tank, the front LOX tank empties approximately 46 seconds after engine start, with a corresponding g-angle of $-35^{\circ}$. Given this g-angle, the minimum DRM2 forward LOX tank residual occurs for a siphon cut-angle of $-50^{\circ}$ (see Fig. 9). Thus, the cases analyzed are for forward LOX tank siphon cut-angles from $-50^{\circ}$ to $-90^{\circ}$.

\section{Analysis Results}

Table 1 lists feasibility analysis results for the range of forward LOX tank siphon cut-angles considered. A forward LOX tank siphon cut-angle of $-50^{\circ}$ results in $28,290 \mathrm{lbm}$ of the total usable propellant, thus exceeding the requirement by 790 $\mathrm{lbm}$. This configuration also requires the vehicle to attain a DRM $3 \mathrm{~g}$-angle of $-89^{\circ}$ to meet the maximum landing propellant residual requirement. Simulations of the DRM3 glide trajectory suggest a maximum safely attainable $\mathrm{g}$-angle of $-94^{\circ}$ for the $\mathrm{X}-34$ vehicle. From Table 1, a forward LOX tank siphon cut-angle of $-90^{\circ}$ corresponds to a required DRM3 g-angle of $-94^{\circ}$, but this configuration exceeds the total usable propellant requirement by only $190 \mathrm{lbm}$. Such a small margin with regards to meeting the total usable propellant requirement was deemed unacceptable in light of analysis fidelity and the early stage in MPS design. Thus, RP-1 dump/feed system design proceeded on the basis of separate dump and feed outlets.

\section{Propellant Dump/Feed Systems Final Layout}

Figure 10 illustrates the final layout for the overall propellant dump and feed systems. The LOX system layout is the same as that in Figure 7. The aft LOX tank uses dual outlets with dump siphon and feed outlet cut-angles corresponding to $-90^{\circ}$ and $0^{\circ}$, respectively, to minimize propellant residual in this tank.

The forward LOX tank uses a single siphon type outlet for both dump and feed scenarios. A siphon cut-angle of $-50^{\circ}$ was desired to minimize propellant residual mass during engine feed, but manufacturing concerns required a compromise effective cut-angle of $-62^{\circ}$. The compromise design reduces dump residual propellant, and comfortably meets usable propellant requirements (ref. Table 1).

Internally, the RP-1 tank outlets are of the same general configuration as for the aft LOX tank. External to the RP-1 tank, the dump and feed lines connect to a common line to transfer RP-1 aft in the vehicle. A common line reduces system dry mass and eliminates the need to route separate dump and feed lines to the vehicle aft, but it does so at the expense of two additional pneumatic valves to isolate dump and feed functions and increased complexity in the design and manufacture of the line itself. 


\section{Preliminary Draft}

Total usable propellant in a full-performance mission for the final system is estimated at 27760 $\mathrm{lbm}$, or $160 \mathrm{lbm}$ above the $27,500 \mathrm{lbm}$ requirement. Total propellant residual in an abort mission is estimated at $1015 \mathrm{lbm}$, or $360 \mathrm{lbm}$ below the 1375 $\mathrm{lbm}$ requirement, based on the final MPS design and a g-angle of $-95^{\circ}$.

\section{LOX DUMP SYSTEM EXIT ORIFICE}

The attached material documents the analysis of the X-34 LOX dump system exit orifice. An orifice is required at the dump line exit to raise the static pressure within the system during high altitude operation. Without an orifice, static pressures within the dump system will drop below the saturation pressure of the LOX and vaporization will occur. Vaporization is undesirable because of large density changes that lead to dangerously high flow velocities, as well as unreliable flow measurements from the LOX dump flow meter.

A preliminary orifice size was determined using the Generalized Fluid System Simulation Program (GFSSP) and an estimated flow coefficient to model the orifice performance. The preliminary orifice operation was then simulated by a three dimensional Computational Fluid Dynamics (CFD) code. The CFD results were then used along with GFSSP to determine a more accurate flow coefficient. This final adjusted orifice flow coefficient was used in a GFSSP model of the entire LOX dump system to determine system performance.

\section{Introduction}

An orifice is required at the dump line exit to raise the static pressure within the system during high altitude operation. Without an orifice, static pressures within the dump system will drop below the saturation pressure of the LOX to be dumped, and vaporization will occur. Vaporization is undesirable because of large density changes that lead to high flow velocities, as well as unreliable flow measurements from the LOX dump flow meter.

During normal (DRM 3) dump system operation, the dump exit pressure will be as low as 3 psia. The dump sequence after a DRM 1 may involve exit pressures $<3$ psia. The LOX dump exit orifice must provide a pressure drop large enough to maintain the static pressure within the dump system above 13 psia. Preliminary GFSSP simulations of the LOX dump system indicate that a 3" orifice at the exit of the 3.834" ID dump line will provide a pressure drop of $\sim 16 \mathrm{psi}$ for a dump flow rate of $146 \mathrm{lbm} / \mathrm{sec}$. This simulation uses an estimated flow coefficient of 0.7858 to model the orifice performance. However, this value was estimated using single fluid approximations. In reality, the downstream side of the orifice will be a two fluid, two phase flow field. A CFD simulation of the dump exit was performed to better estimate the orifice performance.

\section{CFD Simulation of Orifice Performance}

CFD simulations of the LOX dump system exit include 20" of 3.834" ID tubing and a 3" orifice. The mass flow rate is set at $146 \mathrm{lbm} / \mathrm{sec}, \rho=71.6 \mathrm{lbm} / \mathrm{ft} 3$ and $\mu=1.31 \mathrm{lbm} / \mathrm{ft}-\mathrm{sec}$. The centerline pressure profile predicted by the CFD simulation is presented in Figure 1.

The pressure profile in Figure 1 indicates that the dump exit orifice produces a pressure drop of 11.5 psi for a mass flow rate of $146 \mathrm{lbm} / \mathrm{sec}$. The pressure 20 " upstream of the orifice is 14.9 psia and the ambient pressure downstream of the orifice is $3 \mathrm{psia}$.

\section{Orifice Flow Coefficient Determination}

The exit portion of the LOX dump system modeled in the CFD simulation was also modeled by GFSSP. With identical pressure boundary conditions and fluid properties, the flow coefficient of the orifice was adjusted in the GFSSP model until the predicted flow rate and pressure drop matched the results of the CFD simulation. With an orifice flow coefficient of 1.0750 , the GFSSP model predicts a pressure drop of $11.5 \mathrm{psia}$ and a flow rate of $146 \mathrm{lbm} / \mathrm{sec}$.

\section{LOX Dump System Performance Simulation}

GFSSP simulation of the entire dump system were rerun with the corrected orifice flow coefficient. Results for various operating conditions are presented in Table 2.

\section{Table 2. LOX Dump System Performance} Simulation Results

The minimum static pressure within the dump system is the exit pressure plus the orifice pressure drop. The results presented in Table 2 indicate that even at very low exit pressures, the orifice will maintain the static pressure within the dump system above 14 psia. 


\section{Preliminary Draft}

Under normal (DRM3) dump procedures, the minimum dump exit pressure will be $\sim 3$ psia. Table 2 indicates that, under these conditions, the minimum static pressure within the dump system will be 16.5 psia. This pressure will eliminate vaporization for LOX temperatures as high as $164^{\circ} \mathrm{R}$.

The final dump exit orifice specifications are given in Table 3. It is important to note that the recommended orifice size is based on a dump line inside diameter of 3.834". Any changes in the line size will effect the required orifice size.

\section{SUMMARY}

Feed systems have been designed which fulfill design requirements for the $\mathrm{X}-34$ hypersonic research vehicle. The resultant feed system design supports engine propellant flow rate and turbopump Net Positive Suction Pressure (NPSP) requirements and accommodates engine thrust vectoring as required for vehicle control. The LOX feed system was reviewed in greater detail than the RP-1 feed system, as it contains components related to the use of dual LOX tanks not present in the RP- 1 system. The LOX and RP-1 feed systems are very similar in function/design.

Propellant tank pressurization profiles meeting both tank Maximum Expected Operating Pressure (MEOP) and main engine turbopump NPSP requirements is presented. The LOX tank pressurization profile requires a drop in ullage pressure during flight to stay within tank MEOP, while the RP-1 results allow pressurant flow to be cut off during engine operation to conserve helium pressurant.

The analyses of propellant tank ullage motion between release of the X-34 from its carry vehicle suggests there to be no problem with the ingestion of ullage gas into the RP- 1 feed system at engine start. Analysis of the LOX system revealed the possibility of the ingestion of a small volume of ullage at engine start. As a result, the maximum time between the last propellant conditioning vent cycle and tank pressurization is limited to 20 seconds, which ensures the collapse of the gaseous oxygen ullage existing near the saturation curve into a sub-cooled LOX state eliminating the possibility of ullage ingestion.

The last analyses provide insight into the terminal drain characteristics of the LOX and RP-1 tanks. These terminal drain analyses result in conservative estimates of the residual propellant mass. Similar analyses may also be useful in determining the timing of engine shutdown in a full performance mission.

\section{ACKNOWLEDGEMENTS}

The authors acknowledge Brian Winters, the X-34 Program "place title here" with Orbital Sciences Corporation for providing technical information and addressing analysis/design issues related to the MPS. Thanks also to the Orbital GNC group for providing trajectory simulation data and related technical interface. Thanks to the technical support engineers at Flow Science, Incorporated for rapid, and always relevant, responses to issues/questions related to Flow $3 D^{6}$.

\section{REFERENCES}

1. Fisher, M. and Ise, M. (1998), "Low Cost Propulsion Technology at the Marshall Space Flight Center -Fastrac Engine and The Propulsion Test Article," AIAA Paper No. AIAA-98-3365.

2. Sgarlata, P. and Winters, B. (1997), “X-34 Propulsion System Design,” AIAA Paper No. AIAA-97-3304.

3. Sullivan, B. and Winters, B. (1998), "Propulsion System Overview," AIAA Paper No.

AIAA-98-3516.

4. Hedayat, A., Steadman, T.E., Brown, T.M., Knight, K.C., White, C.E., Jr. and Champion, R.H., Jr. (1998), "Pressurization, Pneumatic, and Vent Subsystems of the X-34 Main Propulsion System," AIAA Paper No. AIAA-98-3519.

5. Brown, T.M., McDonald, J.P., Hedayat, A., Knight, K.C., and Champion, R.H., Jr. (1998), "Propellant Management and Conditioning Within the X-34 Main Propulsion System," AIAA Paper No. AIAA-98-3518.

6. McDonald, J.P., Minor, R.B., Knight, K.C., Russell, F.J., Jr. and Champion, R.H., Jr. (1998), "Propellant Feed Subsystem for the X-34 Main Propulsion System," AIAA Paper No. AIAA-98-3517. 


\section{Preliminary Draft}

7. Majumdar, A. K., Bailey J. W., Schallhorn, P. A., and Steadman T.,(1998) "A Generalized Fluid System Simulation Program to Model Flow

8. FLOW-3D Version 6.0, Flow Science, Inc., Los Alamos, NM

Distribution in Fluid Networks," AIAA paper, AIAA 98-3682. 


\section{Preliminary Draft}

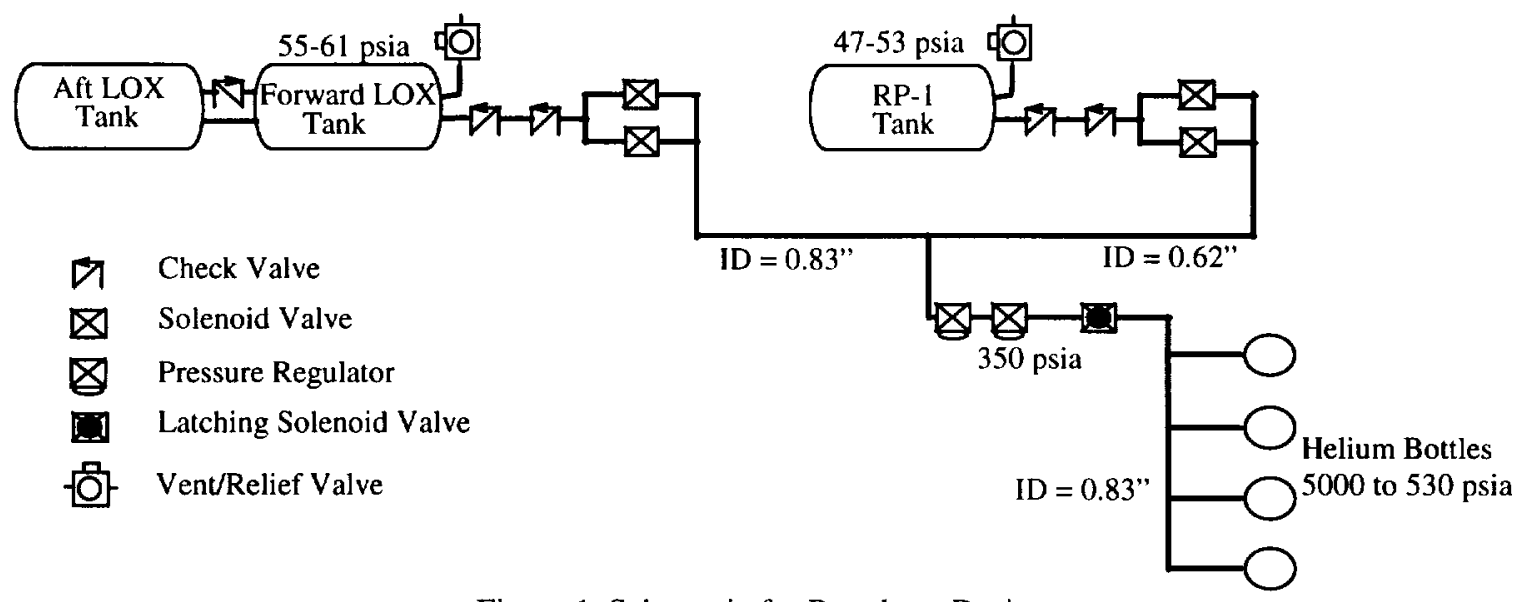

Figure 1. Schematic for Regulator Design.

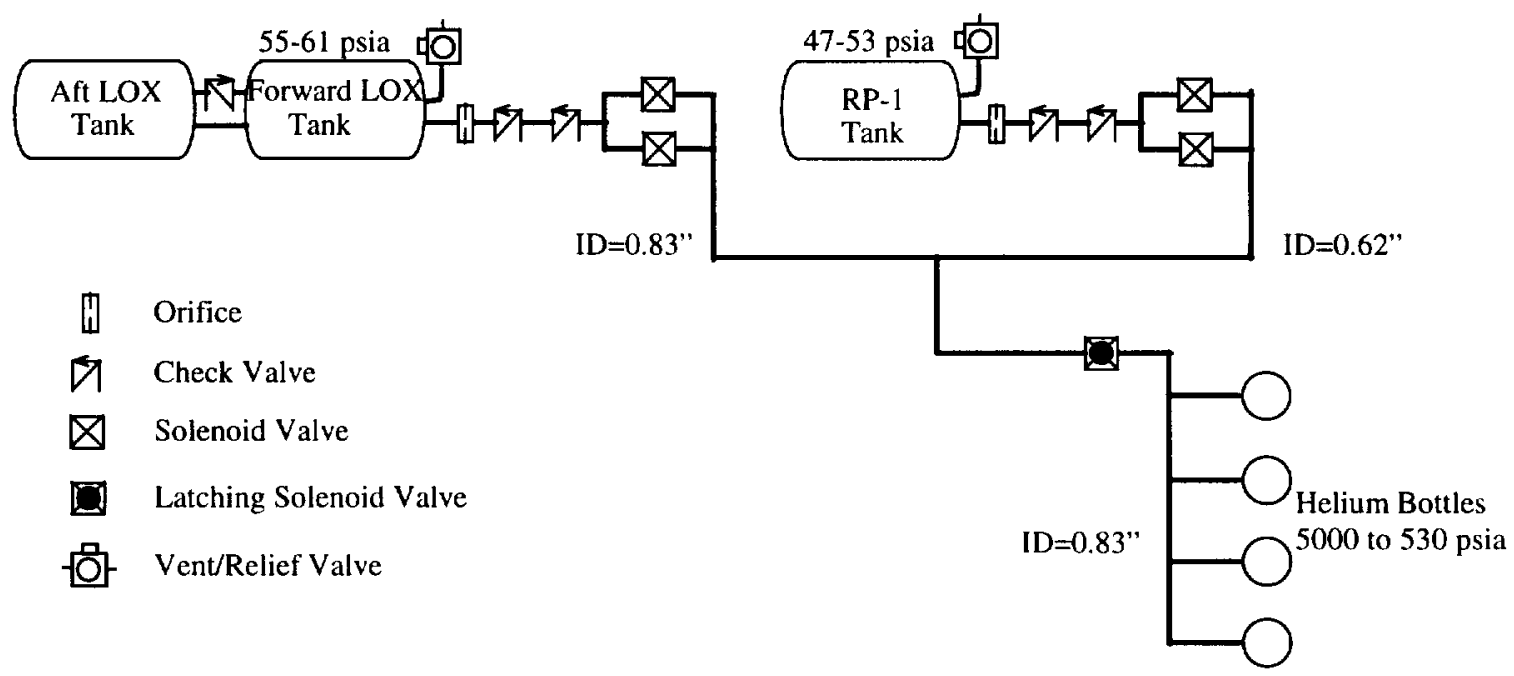

Figure 2. Schematic for Single Orifice Design.

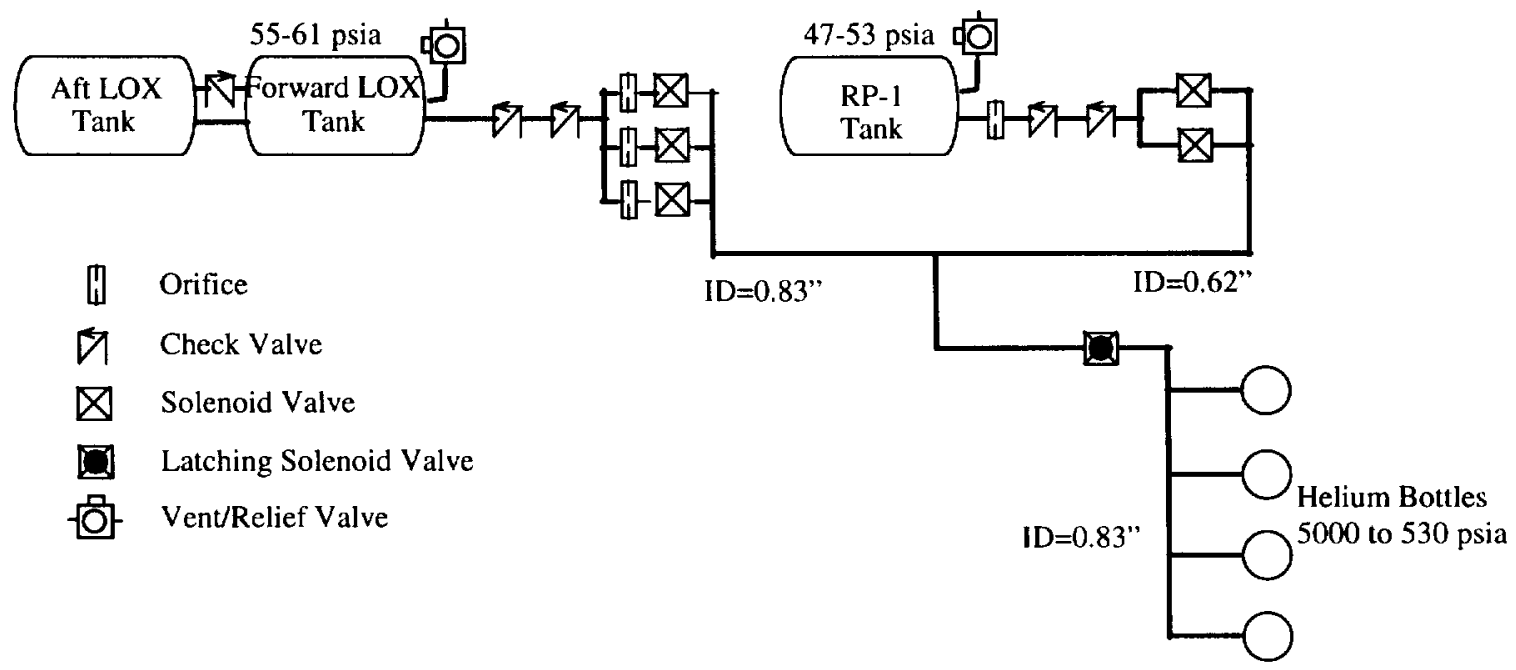

Figure 3. Schematic for Multiple Orifice Design. 


\section{Preliminary Draft}

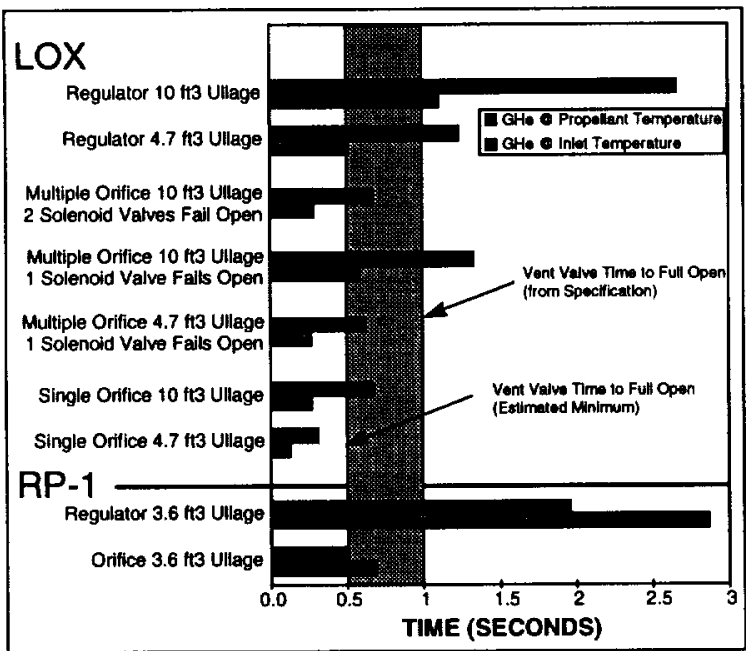

Figure 4. Tank Pressure Rise Time to Proof.

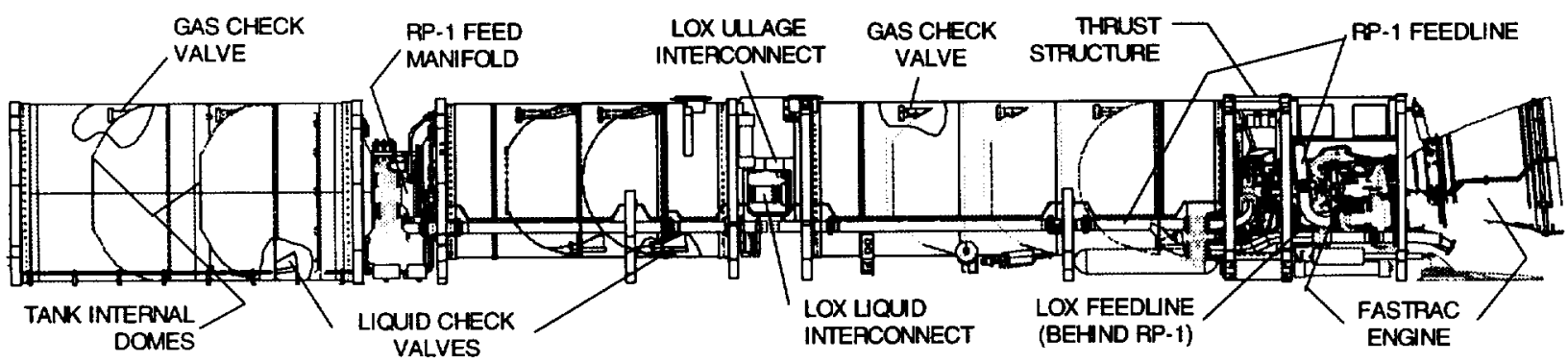

Figure 5. X-34 MPS Elevation View.

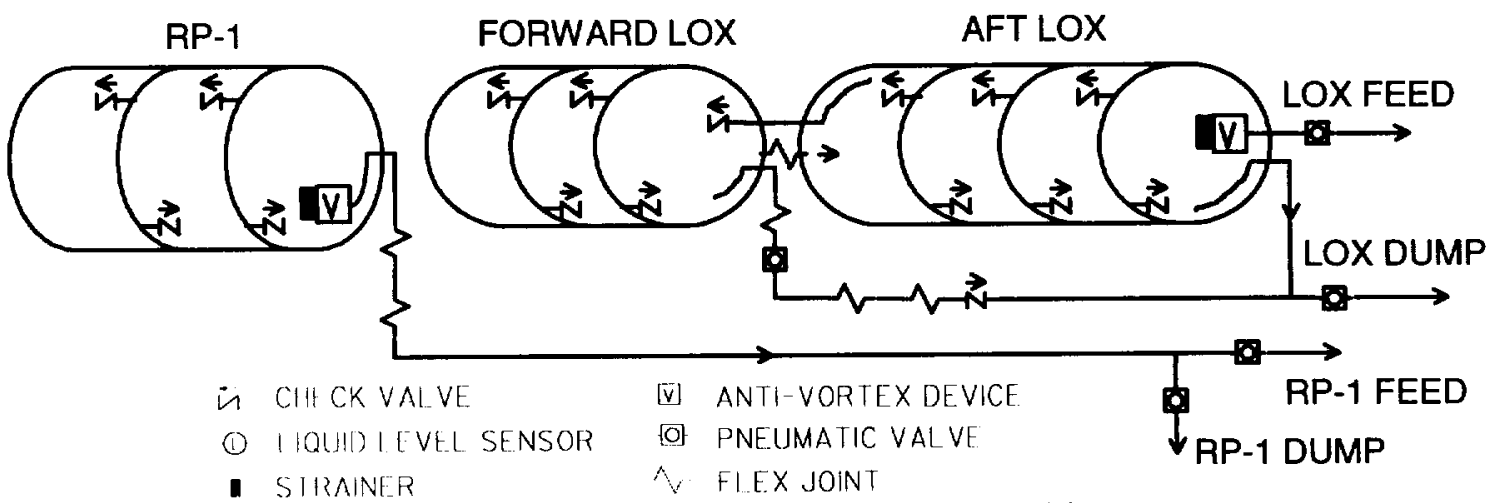

Figure 6. Initial Trial Layout of the Dump and Feed Systems. 


\section{Preliminary Draft}

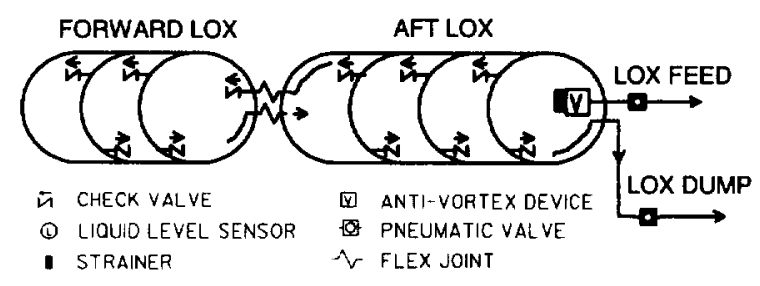

Figure 7. Revised LOX Dump/Feed System Layout.

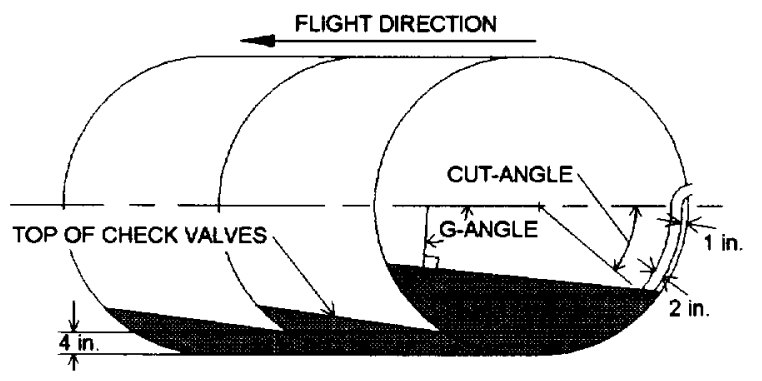

Figure 8. Tank Geometry Assumed for Analysis.

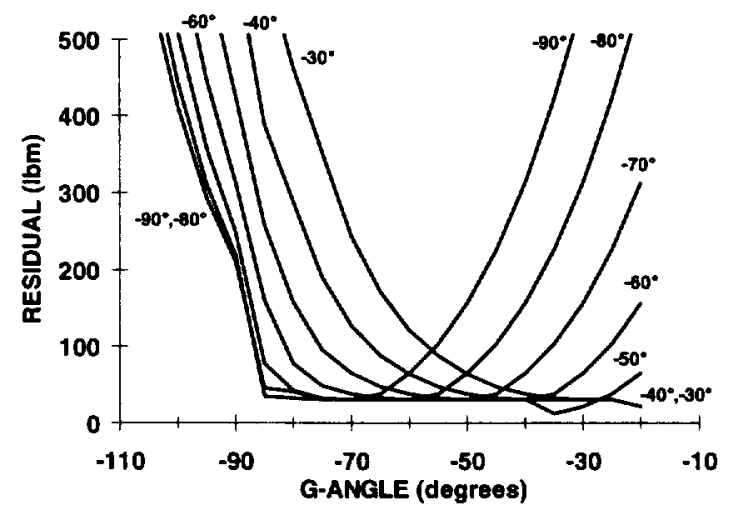

Figure 9. Forward LOX Tank Residual Map for Cut-angles from $-30^{\circ}$ to $-90^{\circ}$.

Forward LOX

Siphon Cut-angle

(degrees)

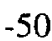

$-60$

$-70$

$-80$

$-90$
Forward LOX DRM2 Residual (lbm)

12

38

102

225

421

\begin{abstract}
RP-1
Dump Cut-angle (degrees)
\end{abstract}

-41
-44
-48
-53
-56
Required DRM3 G-angle (degrees)

$-83$

$-85$

$-87$

$-93$

$-94$
Total Usable Propellant (lbm)

28290

28250

28160

27980

27690

Table 1. Summary of Analysis Results. 


\section{Preliminary Draft}

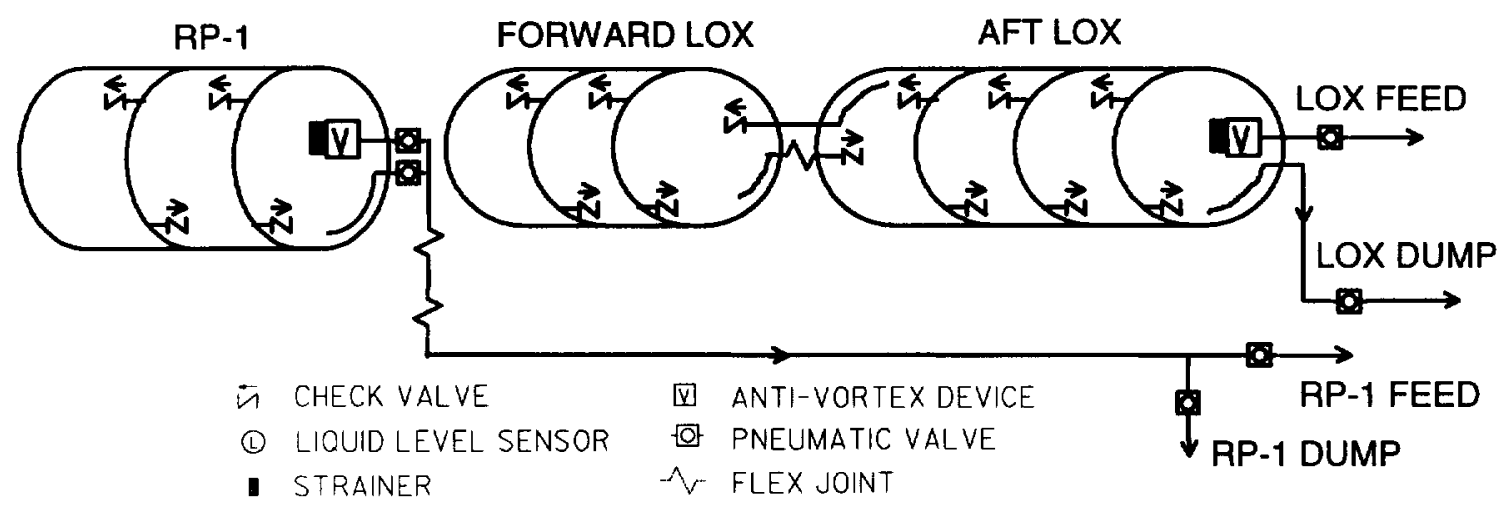

Figure 10. Final Layout of the Dump and Feed Systems.

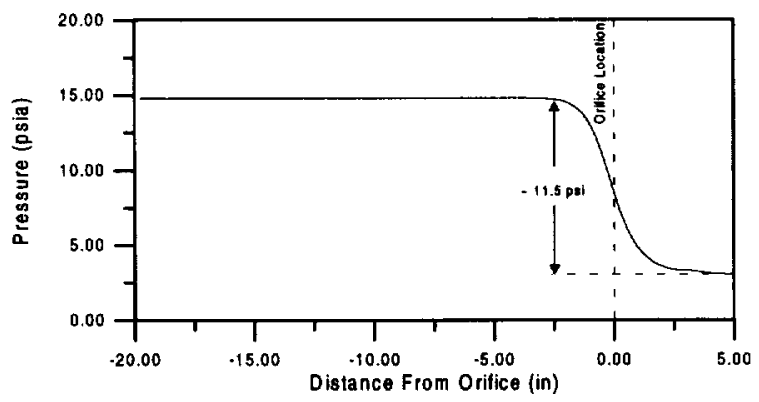

Figure 10. CFD Simulation Results of Centerline Static Pressure near the LOX Dump System Exit.

$\begin{array}{cccc}\begin{array}{c}\text { Tank } \\ \text { Pressure } \\ \text { (psia) }\end{array} & \begin{array}{c}\text { Exit } \\ \text { Pressure } \\ \text { (psia) }\end{array} & \begin{array}{c}\text { Flow } \\ \text { Rate } \\ (\mathrm{lbm} / \mathrm{s})\end{array} & \begin{array}{c}\text { Orifice } \\ \Delta \mathrm{P} \\ (\mathrm{psi})\end{array} \\ 58 & 15 & 140 & 10.5 \\ 58 & 13 & 143 & 11.0 \\ 58 & 10 & 147 & 11.8 \\ 58 & 8 & 151 & 12.3 \\ 58 & 6 & 154 & 12.7 \\ 58 & 4 & 156 & 13.2 \\ 58 & 3 & 158 & 13.5 \\ 58 & 0.5 & 161 & 14.1\end{array}$

Table 2. LOX Dump System Performance Simulation Results 
Orifice Diameter (in.) $\quad 3.000$

Dump Line Inside $\quad 3.384$

Diameter (in.)

Beta Ratio $\quad 0.782$

Flow Coefficient $\quad 1.075$

CFD/GFSSP Reference Point: $\Delta \mathrm{P}=11.5 \mathrm{psia}$, flow rate $=146 \mathrm{lbm} / \mathrm{s},\left(\rho=71.6 \mathrm{lbm} / \mathrm{ft}^{3}\right.$;

$\left.\mu=1.365 \times 10^{-4} \mathrm{lbm} / \mathrm{ft}-\mathrm{s}\right)$

Table 3. LOX Dump Exit Orifice Specifications. 